\title{
Digital Transformation of Traditional Chinese Banks
}

\author{
Ziyun Shu ${ }^{1^{* \#}, \text { Shuk-Yu Tsang2*, Taoxuan Zhao }}{ }^{3^{*}}$ \\ ${ }^{1}$ Sichuan International Studies University, Chongqing, China \\ ${ }^{2}$ Po Leung Kuk Celine Ho Yam Tong College, Hongkong, China \\ ${ }^{3}$ Tianjin Yaohua High School, Tianjin, China \\ Email: "cis2018@foxmail.com
}

How to cite this paper: Shu, Z.Y., Tsang, S.-Y. and Zhao, T.X. (2020) Digital Transformation of Traditional Chinese Banks. Open Journal of Business and Management, 8, 68-77.

https://doi.org/10.4236/ojbm.2020.81005

Received: September 16, 2019

Accepted: December 6, 2019

Published: December 9, 2019

Copyright $\odot 2020$ by author(s) and Scientific Research Publishing Inc. This work is licensed under the Creative Commons Attribution-NonCommercial International License (CC BY-NC 4.0).

http://creativecommons.org/licenses/by-nc/4.0/

\begin{abstract}
The paper examines the status quo of traditional Chinese banks under the attack of the new digital giants in China-Alibaba (Alipay) and Tencent (WeChat). Traditional banks urgently need their own analysis and corresponding changes in order to stand out in the tide of the times and not be oppressed by digital giants. Banks have also launched their own e-commerce platform, but there are many shortcomings. Based on the analysis of characteristics of digital platforms, the paper put forward corresponding suggestions to banks in the ecosystem to better cope with future opportunities and challenges. Using a case study approach showing the traditional services provided by CCB's mobile banking (China Construction Bank, one of the famous traditional banks in China) and corresponding improvements, the paper concludes that traditional Chinese Banks can protect themselves in four ways-emphasizing more on digital platform services, designing credit card platform, cooperating with third party on the platform, and establishing E-commerce and bank APP for users.
\end{abstract}

\section{Keywords}

Digital Giants, CCB (China Construction Bank), QR Code, Sensor, App, Digital Platform Services

\section{Introduction}

In recent years the banking industry has seen a large influx of new digital players. Foremost among them are digital titans such as Alibaba and Tencent who have experienced some rapid growth in the last few years. In the last four years,

*These authors are co-first authors, sorted by alphabetical order of the last name. 
Alibaba, a new entrant to Chinese financial market, grew at $408 \%$, making it an absolute leader in lending. In 2017, Alibaba issued SME (Small and Medium Enterprises) loans worth 446 billion RMB. Around the same time, Alipay-a payment app affiliated to Alibaba Company-attracted deposits of 1.6 trillion RMB, which equaled to $89 \%$ of the deposits gained by Bank of China. Like Alipay, Tencent also expanded its services into payments to support more than $80 \%$ online activities of modern Chinese.

Previous banks were simply face-to-face counter services. Today's traditional banking industry divides business scenarios into online and offline. Off-line, they handle various banking services for people at their own business locations. On the other hand, they launched their own mobile banking APP online to provide people with convenient and fast online services, people can transfer money and other operations anytime, anywhere on the mobile phone.

With the introduction of online banking, people's life is more convenient and fast. However, due to the low market penetration and the low utilization rate of people, the banking performance has not been greatly improved. We want to add a "sensor" to establish a link between customers and banks, and use customers' instant information to improve customers' services better and more.

It is worth adding sensors to the business of traditional banks, integrating two-dimensional codes into credit card payment, using user information of third-party platform to provide relevant financial services, and creating an e-commerce platform belonging to the bank itself to provide online shopping services for users. Finally, we will further improve the function design of APP in online banking to meet the basic business needs of customers. This paper is based on the era of the vigorous development of the Internet. We study and discuss how the traditional banks should survive in the current market environment, and provide a certain opinion on the future development of the traditional banks and the digital transformation of other traditional financial industries.

\section{Background}

\subsection{Digital Banking: Full Digital Banking Platforms}

Digital banking can be divided into three categories. The first category is full digital banking platforms such as Alipay and Tencent. As we all know, Alibaba started with Taobao, an e-commerce platform and Tencent began with WeChat, a social networking software. What they have in common is that over time, they can accumulate millions of users on their own platforms. With a certain user base, they gradually began to expand their business areas and launched with QR (Quick Response) code payment on the basis of people's needs. In the context of mobile payment services, users who perceive benefits from using the third-party mobile payment platform may perceive more compatible. Because user's lifestyles will strongly affect their beliefs, attitudes, trust and intention toward adoption [1]. It gradually penetrates into people's lives and changes people's consumption mode little by little. In China, people are not in the habit of using cre- 
dit cards, and the way of cash payment is not convenient for people. QR code scanning is fast and convenient, giving these full digital banking platforms a chance to invade Chinese traditional banking industry. One huge impact of such invasion is the gradual fade of cash consumption. In 2019, iResearch data showed that China's third party mobile payment market still maintained a relatively concentrated market share. The first tier Alibaba's Alipay accounted for $53.8 \%$ and $54.2 \%$ of the market share in Q1 and Q2 respectively. Tencent's fortunes accounted for $39.9 \%$ and $39.5 \%$ of the market share respectively in Q1 and Q2. ${ }^{1}$ As we can see, almost everyone has been accustomed to the new way of payment.

In 2004, Alipay officially separated from Taobao, specializing in payment platform. Now Alipay's e-payment has almost covered all the electronic payment platforms in China. As the number of online shoppers increases annually, Alibaba's advantage of relying one-commerce platform is becoming more and more obvious. While purchasing on its e-commerce platform "Taobao", people directly pay their commodities through Alipay-thus a thorough chain is formed from the beginning to the end. As a result, Alipay's mobile payment market share will further expand.

In conclusion, the similarity between Alipay and WeChat is that they all transformed from a platform amassing thousands of users to a third-party payment platform, and then slowly expanded from the third-party payment business to the lending business, and so on. In its early time, Alipay only provided its mother app "Taobao" with guaranteed payment service. Since then, the scope has been gradually enlarged to the use of merchants and scenarios, and also launched credit card repayment, charity payment and other services, just like you can go to the supermarket by scanning the QR code to pay. Same pattern is also accomplished on Tencent's social media app "WeChat". When you take the taxi, you can pay by WeChat on mobile phone. There is no need to turn over the bag for your wallet and arduously count the money any more. As new titans in the field of payment, WeChat and Alipay successfully predicted the future tendency - no cash payment is required, and their customer group is the general public.

\subsection{Digital Banking: Fintechs}

The second category comprises of Fintechs (Financial Technology companies) which are mainly driven by data and technology and are changing the ecological pattern of the financial industry. As for the application of financial technology, Citigroup has reported that the total investment attracted by financial technology in the past five years was close to $\$ 50$ billion, from $\$ 1.8$ billion in 2010 to $\$ 19.1$ billion in 2015. China is particularly prominent in the particularly fast-growing economies. In 2016, KPMG and CB Insights published quarterly financial technology industry pulsation data, showing that in the first quarter of

${ }^{1}$ Data Resource: https://www.iresearch.com.cn/Detail/report?id=3454\&isfree=0. 
2016, Chinese financial technology companies supported by venture capital attracted 2.4 billion US dollars in investment, accounting for 4.9 billion US dollars a year in the world. Regardless of the amount of investment and financing, as well as the size of the market and the number of leading enterprises, Chinese financial technology in 2016 has begun to take over from the shrinking western market and become a leader in the field of global financial science and technology. The huge number of users, unlimited potential market space and new technologies that are rapidly applied to various fields have provided China with the soil for the emergence of world-leading Fintech giants.

The industry regulation rules and Matthew effect are ameliorated day after day, which makes the industry accelerate towards a standardized development, and some large Fintech groups are forming. Typical representations like Ant Financial Service Group, Jingdong Finance, Lufax and Van Pujinke are standing out and occupying a place in the world's financial and technological territory. Alibaba is expanding its presence globally, and transforming traditional payment systems. As a result, traditional financial services companies are cautious about new fintech startups, which are disrupting their traditional business territory [2]. They utilize big data, block chains and other Internet innovation technology to control risks within a minimum level as well as manage platforms.

\subsection{Digital Banking: Online Banking}

The third category comprises of traditional banks that are attempting to engage in digital transformation. Digital banking refers to a variety of financial services provided by banks to customers through Internet technology or other public information networks through personal computers or other smart devices. The online banking business not only covers the traditional banking business, but also breaks the boundary of banking operations and penetrates into the fields of securities, insurance and even commercial circulation. Mobile banking is an extension of online banking. It is a convenient financial service mode for bank users after online banking and telephone banking, thus owns the name of "electronic wallet". On one hand, it prolongs the service time of banks and extends the scope of banking services; on the other hand, it invisibly increases many banking branches, truly realizes 24-hour-full-time service, and vigorously expands the intermediary business of banks. At present, China Merchants Bank, Bank of China, China Construction Bank, Bank of Communications, Guangdong Development Bank, Shenzhen Development Bank and CITIC Bank are the banks that open mobile banking business in China. Their business can be roughly divided into three categories:

1) Fee checking business: including account inquiry, balance inquiry, account details, transfer, water and electricity charges collected by banks, telephone charges and so on;

2) Shopping business: referring to the purchase business. After the customer binds the mobile phone information to the banking system, they buy goods through the mobile phone banking platform; 
3) Financial management business: including stock speculation, foreign exchange speculation and so on.

In summary, we expect the traditional banks to change to the first two categories or improve their performance of mobile banking mentioned in the last categories. We also expect to see traditional banking being disrupted adapt to new digital technologies and learn how to leverage them in their business models.

\section{Disruption in Traditional Banking by Alibaba and Tencent}

Nowadays, the use of data is ubiquitous in all fields. The explosive growth of big data has completely broken the tranquility of traditional banks. Traditional banks no longer stick to the traditional entity business model, it began to digital transformation. In the traditional business model, there is a consumer ecosystem, which centers on the needs of consumers. Business activities of enterprises are carried out around it. After meeting the needs of customers, the transaction ends. In the traditional business mode, there is a production ecosystem, centered on products, relying on a complete production and supply chain. The business of the enterprise is launched around it. After the product is completed and delivered to the customer, the transaction is completed and terminated. In the later business model, the consumer ecosystem is excavating the greater value of data. In this new ecosystem, transaction is not only limited to a simple transaction, but also the integration of real-time customer data, tapping the potential needs of customers, providing further channels to stimulate customers' consumption behavior, so as to expand business to other areas of consumer demand.

Nowadays, it is undeniable that WeChat and Alipay have brought a lot of crackdown on traditional banking industry. The traditional banks belong to pipelines, which meanly focuses on offering services to people, whereas Tencent and Alibaba are digital platforms that pursue more interactions after purchasing and provide more related services based on real time information...As we all know, Tencent's WeChat is based on social app and Alibaba's Alipay is based on the rise of the e-commerce platform-Taobao. On these core inter-related components in their platform, they set up a large number of users before developing other business. On the one hand, the financial products launched by WeChat and Alipay, such as WeChat's CAITONG and Alipay's balance treasure, are undoubtedly the oppressor of traditional bank financial products. WeChat and Alipay's sweeping code payment has gradually changed people's way of life. People began to get used to going out without cash and paying with mobile phone scanner wherever they went. In this way, the concept of mobile payment appears in people's vision. Initially, Alipay was designed as an online payment platform for Taobao (taobao.com), which is an online shopping website like Amazon and eBay. On May 26, 2011, Alipay obtained the first Payment Business Permit issued by the People's Bank of China, which allows its users to make payments to their friends, to mobile phone companies, prepaid cards, and municipal services [3]. In addition, Alipay's Hua Bai is also an impact on bank cre- 
dit card business. Alibaba makes use of its own e-commerce platform to effectively analyze users' records in Taobao shopping to obtain more real time information such as consumption level, cosumer preferences, etc., and then push specific messages to users in Alipay. Tencent uses WeChat, its largest social media network, to obtain users' information and recommend public accounts and financial products in WeChat. By comparison, traditional Banks are eclipsed.

\section{What Are Traditional Banks Doing?}

Nowadays, we are in the world of changing. As the Internet and online services became more and more pervasive, most traditional banks in China sensed the status quo and began to establish platforms called Mobile banking, which offered a variety of traditional services in the apps of banks for their customers. Mobile banking, as one of the ubiquitous services in China these years, is synthesizing the current tendency of mobile communication with money digitalization. In this enormous wave of transformation, the mobile banking app of China Construction Bank (CCB) outperformed other banks' apps and quickly rooted in the Chinese market. Therefore, we will use CCB's mobile banking as a case to analyze its functions and possible improvements towards full digital platforms.

1) Account Inquiry.

This function is able to meet customers' needs about immediately acquiring related information of the registered banking account, and further provides checking balance, summary of transaction details and assets report to the users.

2) Transfer accounts and Remittance

Apart from the traditional ways of transfers, CCB is extremely appealing when it first utilized " $\mathrm{C} 2 \mathrm{C}$ " mode in the mobile banking, which allows direct transfers from one consumer to another consumer.

3) Bill payment and Online payment

This function mainly offers customers the service of paying phone bill and some everyday necessities like electricity costs, which makes people's lives convenient without running about. The online payment is further guaranteed as advanced technologies like dynamic password, USB key is used to safeguard the paying process. And users are able to check the record of consumption during a few months.

4) Investment and finance

The users can purchase foreign exchange, gold, funds, national debts and other common investments on the mobile banking of CCB.

5) Loan management

This function offered history query of loan repayment record, reminder of overdue loans and calculation of prepayment.

6) Credit Card Business

The app is able to help the customers check accounts and scores, conduct repayments and handle installments, etc. Besides, when purchasing on CCB's Shanrong online shopping mall, customers who use credit cards of CCB will 
gain some scores to counteract part of the price according to the ratio 1000 to 2, which makes the products cheaper.

We can see that the mobile banking of CCB not only replicates the traditional business in bank branches, but also builds its own platform around integration of business and finance, which plays a greater role in the process of "pipeline business". People can use their credit cards to buy goods they want with interest-free installments on this e-commerce platform. But there are some disadvantages on the design of this platform that makes CCB's mobile banking pale when competing with new entrants like Alibaba and Tencent. Recently, some traditional e-commerce platforms in China began to divide the huge cake of Chinese financial market, attacking CCB and other traditional banks from both "the pipeline services" and "digital platform services" through collecting real-time information and generating more value from them. [4] Let us first have a brief overlook around the disadvantages of CCB's mobile banking.

First, the operation process is too tedious compared with the services of Alibaba's Alipay and Tencent's Wechat Pay. Take the process of applying loans as an example. When operating on mobile banking or any bank branches, the customers have to go through a serious of inflexible stages involving first submit an application, then wait for processing and assessing the application, release the loans, and finally repay the loans. The whole process may take two or a few days. If people choose to apply loan through private enterprise like Alibaba's Ant Financial (Alipay, Ant Check Later, and Yu'EBao are all subordinated to Ant Financial), it only takes a few minutes to finish the whole process on Ant Check Later. Even customers are able to enjoy interest-free installment if they buy products on Alibaba's e-commerce platform “Taobao”. Similar situation happens when the customers hope to withdraw cash or use other services on CCB's mobile banking.

Second, and the most important, the mobile banking of CCB only focuses on its "pipeline services" and ignores the potential of "digital platform". It failed to create connection between different groups of people and capture customers' real time information to offer more humanized service after customers consumed on its platform. Platform businesses bring together producers and consumers in high-value exchanges. Their chief assets are information and interactions, which together are also the source of the value they create and their competitive advantage [5]. On the other hand, CCB's new competitor Alipay actively aggregates customers' real time information and further utilizes them by personal recommendation including finance, everyday necessities and other products that people are most likely desperate for. From this perspective, we can see that the mobile banking of CCB is only an online extension of its original services, and the purpose of traditional bank is to profit from its original "pipeline", instead of the "digital platform" that mains threats will come from.

\section{What More Can They Do?}

Although the current traditional banks have not completed the digital transfor- 
mation, due to the mature technology of sensors in mobile devices, traditional banks will have a lot of opportunities to enter the consumption ecosystem to compete with digital giants.

\subsection{Overview of the Design of Credit Card Platform}

Because companies such as Alibaba and Tencent are unable to issue and manage credit card business, only banks can do so. At the same time, credit cards have great potential in China and there is much room for development. If credit cards can be combined with technology such as Internet and sensors, it may have a positive impact on the transformation of traditional banks. Because of the inconvenience of carrying credit cards, we can use two-dimensional codes (QR Codes) as sensors to make banks a platform. We can build some roles on the platform: banks, third party participants, e-commerce, users and so on. All transactions can be completed on the platform and all interactions can be implemented on the platform.

\subsection{The Effects of Sensor}

In this way, banks have the opportunity to get users' real-time information through sensor to understand users' shopping preferences, buying habits, consumer demands and so on, so that banks can expand their business to consumption ecosystems. Banks will introduce their own two-dimensional code for credit card consumption. People can buy goods offline by using mobile phones to make sweep payment. At this time, mobile phones will become "walking credit cards". Sweeping credit card consumption mode is less cumbersome steps of POS machine, its convenient and fast characteristics will become the first choice of people's consumption mode in advance. At the same time, the financial services of the bank platform can also process credit cards online for users. On the platform of bank e-commerce, people can use their credit cards as account login anytime and anywhere, and then purchase goods by installment with credit cards on the platform. Taking this platform as the sensor of the bank, the bank will get a large amount of data from the users, which can be analyzed and processed to obtain more useful user information. Once the user's information is available, the bank will have the opportunity to enter the consumption ecosystems. On this platform, different users will be provided with customized investment and financial products services, price reduction reminders of online collections, and so on.

\subsection{Third Party Participants on the Platform (Such as Educational Institutions)}

In addition, traditional banks can cooperate with educational institutions to provide personalized customized credit card processing services to their customers' in-use information and large data analysis. In this way, banks can sign up with educational institutions to provide personalized credit card services for children who want to study abroad. Traditional banks should lower the thre- 
shold of credit card application, give students a certain credit limit to use or launch parent-child cards, with parents as guarantors, children use credit cards for consumption. Traditional banks should change the way credit cards are used. Nowadays, credit cards are limited in use because of POS machines, mostly in shopping malls. If China Construction Bank can launch its own two-dimensional credit card payment code, it will greatly facilitate people's lives and change the way people consume. In China, the concept of early consumption is not popular yet, but it is the main trend in the future. So at the same time, traditional banks can improve their e-commerce platform, improve the usage and penetration of the platform to improve their credit card business. In addition, traditional banks can cooperate with educational institutions to provide personalized customized credit card processing services to their customers' in-use information and large data analysis. In addition, banks can also cooperate with rental intermediaries to expand their credit card field by providing credit card payment services to each user, taking advantage of their rental tendencies.

\subsection{E-Commerce}

In the field of e-commerce, when two or three platforms penetrate into people's lives, the e-commerce market will basically tend to be saturated and become an oligopoly competition mode. At present, Alibaba's Taobao e-commerce platform, Jingdong Mall and NetEase Koala have become unshakable business leaders in online shopping. They mainly focus on third-party online shopping for payment. However, several traditional banks have launched their own e-commerce platform, such as China Construction Bank, which has launched its own financial and business combination of "good financial business" platform. On this platform, users can not only purchase and consume by binding their own credit card login account, but also deal with credit cards online and so on Unlike Taobao, he advocates that users use credit cards to pay interest-free installments according to their own economic conditions. Without the handling fee paid by the third party, the goods on the platform will be much cheaper. On the basis of the establishment of the platform, the original credit card mall can be better utilized after getting all kinds of relevant information from users. We can push products that users like before they buy, recommend complementary products after they buy, and so on. People in the electronic mall can immediately handle credit cards for shopping and consumption, so that there is no money can also have enough quota to buy their favorite commodity services, which Taobaocan not match.

\subsection{Bank APP for Users}

With the concept of ahead-of-time consumption deeply rooted in people's minds in the future, using mobile phone as a "mobile credit card" for consumption will become the first choice for people to consume. Users only need to download the banking platform APP on their mobile phones to pay for online 
scans and online shopping. All-round credit card consumption service will be more convenient for users' life and create a one-stop money pipeline for users. Users can invest and manage money on the platform. They can also spend money on shopping and consumption on the platform. Moreover, they can transfer money instantly on the platform.

\section{Conclusion}

Traditional banks are being suppressed by digital giants, but also because of the emergence of some technologies (sensor application), traditional banks have the opportunity to fight against digital giants. Banks can build their own "one-stop" platform as their own sensors to access user information into the consumer ecosystem. When popularizing the concept of early consumption, banks can further expand their business areas by using credit cards, on the one hand, create a new two-dimensional code of credit card for users to consume, on the other hand, integrate more roles and businesses into their original e-commerce platform, provide users with usage rate, obtain more user information, and provide them with more additional credit card services. Banks with their own sensors will be able to better complete the digital transformation, from pipelines to platforms, and have better development in the future.

\section{Acknowledgements}

This acedemic paper is finished under the guidance of Professor Mohan Subramaniam from Boston College. We want to appreciate every person helping us during three-month long investigation, especially our professor who provided us with business knowledge. In addition, thanks to the CIS platform that helps us to communicate with elites around the world.

\section{Conflicts of Interest}

The authors declare no conflicts of interest regarding the publication of this paper.

\section{References}

[1] Mu, H.L. and Lee, Y.C. (2017) Examining the Influencing Factors of Third-Party Mobile Payment Adoption: A Comparative Study of Alipay and WeChat Pay. The Journal of Information Systems, 26, 257-294.

[2] Shim, Y. and Shin, D.H. (2016) Analyzing China's Fintech Industry from the Perspective of Actor-Network Theory. Telecommunications Policy, 40, 168-181. https://doi.org/10.1016/j.telpol.2015.11.005

[3] Alipay (2014) About Alipay. https://ab.alipay.com/i/jieshao.htm

[4] Subramanian, M., Balalyer and Venkatraman, V. (2018) Competing in Digital Ecosystems.

[5] VanAlstyne, M.W., Parker, G.G. and Choudary, S.P. (2016) Pipelines, Platforms, and the New Rules of Strategy. 